\section{ELECTION TO THE ENGLISH COUNTRY COUNCIL OF THE BRITISH DENTAL ASSOCIATION}

Nominations are sought for by elections to fill vacant seats on the following English Country Council of the British Dental Association (BDA):

- 1 vacancy representing the Central Counties Branch.

The Council has the following remit:

- To provide regular advice and comment to the Principal Executive Committee as a consultative committee

- To consider and advise the Principal Executive Committee on all matters relating to dentistry within England

- To advise the Principal Executive Committee on all aspects of policy within England, facilitating external expert and member input to policy formation where required

- To receive regular reports from the Principal Executive Committee, to enable the Council to debate and comment on the activities of the Principal Executive Committee

- To liaise with branches and sections.

The Country Councils play a vital role in ensuring that the Principal Executive Committee, which is concerned with the strategic direction and governance of the Association, is kept in touch with the views and concerns of members. Country Council members are the 'voice of members' to the Principal Executive Committee and senior management team.

The Country Councils together constitute the United Kingdom Council which, amongst other functions, considers an annual report from the Principal Executive Committee on its strategic priorities and activities.

Term of office

This shall be until February 2018, with the entitlement to stand for a further three-year term of office at that point.

More information about this by-election can be found at: www.bda.org/ elections.

The close of nominations is 17.00, May 232016.

Further information can be obtained by contacting Stephen Skelton on 02075634141 or emailing stephen.skelton@bda.org.

\section{OVERSEAS APPLICANTS WILL HAVE TO PROVE ENGLISH COMPETENCE}

Powers came into force on 1 April 2016 to allow the General Dental Council (GDC) to check the English language competence of any new dentist or dental care professional (DCP) before they can practise in the UK.

A change to European Union law means that all applicants - including those from the European Economic Area (EEA) who were previously exempt from language testing - will need to supply evidence of their ability to communicate effectively in spoken and written English before being allowed on the register.

The change brings EEA candidates into line with applicants from other non-EEA countries who already have to demonstrate their proficiency in English.

Dental professionals qualifying in a country where English is the first and native language will not routinely need to provide additional evidence about their knowledge of English.

The measures introduced follow earlier plans by the Department of Health for English language testing across several healthcare professions including dentistry, nursing and midwifery and pharmacy.

Dentists and DCPs who reapply to the register will also have to meet the same requirements to demonstrate their English language proficiency.

1 April also marks a change to the levels of English required by overseas qualified dental nurses and dental technicians applying to the register. The pass level in the International English Language Testing (IELTS) exam will rise from Level 6 to Level 7 , which is the same level for all other members of the dental team.

\title{
CAN YOU HELP IDENTIFY A BODY FOUND IN CONWY?
}
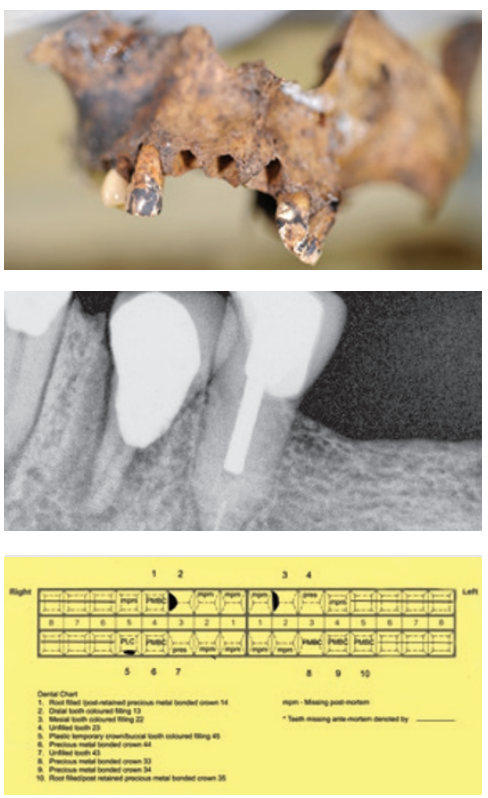

North Wales Police are appealing for dentists' help to identify a body found in Clocaenog Forest in the south of the County of Conwy in November 2015.

The male was aged over 54 , 5'8"-5'101/2" and was probably of a large build. He had sustained serious head trauma and the circumstances of his death are being treated as suspicious.

Due to the state of the remains it is apparent that he had been dead for a number of years. The date of death is thought to be after 2000 .

The services of a forensic odonatologist were used to help identify the remains. The male's dentistry (see images), particularly crown work, is typical of dental procedures common in the UK between 1980 and 2000 . Two of the crowns show evidence of high quality dental procedures.

Unusually one crown was plastic, badly worn and had remedial filling work.

All upper and lower molars had been lost/extracted ante mortem. X-rays of the lower left second pre-molar and upper right first pre-molar illustrate the quality of the dental work.

The full forensic report can be made available should any reader require it for more detailed comparison.

Please contact North Wales Police Major Incident Team:

DC2313 Don Kenyon, don.kenyon@nthwales.pnn. police.uk, 01745588784

Or

DS977 Dewi Jones, dewi.jones3@nthwales.pnn.police. uk, 01407724271.

The News Editor has seven related images in total. Please email k.quinlan@nature.com to view these. 